\title{
The Relationship between Social Identity and Foreign Language Learning Motivation: The Sustainability of Heritage Language Learners
}

\author{
Luis Miguel Dos Santos
}

Endicott College, Woosong University, Daejeon 14696, Korea; luismigueldossantos@yahoo.com

check for updates

Citation: Dos Santos, L.M. The Relationship between Social Identity and Foreign Language Learning Motivation: The Sustainability of Heritage Language Learners. Sustainability 2021, 13, 13102. https:/ / doi.org/10.3390/su132313102

Academic Editors: Xuesong

(Andy) Gao and Mairin

Hennebry-Leung

Received: 11 October 2021

Accepted: 24 November 2021

Published: 26 November 2021

Publisher's Note: MDPI stays neutral with regard to jurisdictional claims in published maps and institutional affiliations.

Copyright: (c) 2021 by the author. Licensee MDPI, Basel, Switzerland. This article is an open access article distributed under the terms and conditions of the Creative Commons Attribution (CC BY) license (https:/ / creativecommons.org/licenses/by/ $4.0 /)$.

\begin{abstract}
This study aimed to explore the relationship between social identity and language learning motivations of a group of heritage Spanish language learners in a university environment in the United States. Based on the qualitative research inquiry with semi-structured interview and focus group activity tools, a group of 78 Spanish language learners in one university environment in the United States were surveyed. Under the open-coding and axial-coding techniques, the finding of this study indicated that the three main motivations were Latinx Americans with dual identities, interests in career development, and surrounding environments and individuals. Department heads, non-profit organisation managers, and researchers may use this study as the blueprint to reform and polish the current foreign language teaching and learning programmes, courses, and policies to meet the expectations of multilingualism.
\end{abstract}

Keywords: foreign language teaching; foreign language learning; heritage language learning; learning behaviour; motivation of learning; second language learning; social cognitive career and motivation theory; social identity; sustainable language learning

\section{Introduction \\ 1.1. Background}

Although there are no official languages in the United States, English is the most commonly spoken language in American communities. According to a recent report [1], besides English, Spanish $(41,757,391)$, Chinese $(3,494,544)$, Tagalog $(1,763,585)$, Vietnamese $(1,570,526)$, Arabic $(1,260,437)$, French $(1,171,775)$, and Korean $(1,075,247)$ have some of the largest populations of speakers in American families. In addition, based on a report by the Modern Language Association (MLA) [2], in 2016, Spanish $(712,240)$ is the most popular foreign language in American schools, followed by French $(175,667)$, German $(80,594)$, Japanese $(68,810)$, Italian $(56,743)$, Chinese $(53,069)$, Arabic $(31,554)$, Latin $(24,866)$, Russian $(10,353)$, Korean $(13,936)$, Ancient Greek $(13,264)$, Portuguese (9827), Biblical Hebrew (9587), and Modern Hebrew (5521). Therefore, Spanish language and Spanish speaking communities play important roles in American society. Although Spanish language and Latinx communities are important to the American communities, Latinx communities and living practices in the United States are still significantly under-researched [3-10]. Therefore, this study worked as one of the latest reports in the fields of language learning motivations and heritage language learning. Heritage language refers to the languages other than the dominant language(s) in the targeted social context and environment. In the United States, English is the de facto dominant language (as the United States does not have any official languages), and English is the primary language employed in the government, education, and social context. Therefore, any language other than English can be understood and viewed as a heritage language for speakers of the language [11].

The historical factors and immigration policies determine the role of Spanish in the United States. Many Spanish language speakers, particularly from Central and South American regions and countries, have moved and settled in different parts of the United 
States. According to a recent report [12], 12\% of the population of Texas consists of Spanish speakers, followed by $11.9 \%$ in California, $9.2 \%$ in Florida, and $8.5 \%$ in Nevada. Another news report [13] indicated that, in the southern region of Texas, such as Laredo, TX and Zapata, TX, more than 50\% of community members speak Spanish as their daily language. Although some studies $[7,14]$ have examined racism and ethnicity issues among these groups, language learning, particularly the relationships between heritage language learning and social identity with the theoretical frameworks of the social identity theory and the social cognitive career and motivation theory, has not been examined. Therefore, the results of this study may outline the ideas beyond the traditional reports with the directions in racism and ethnicity. Social identity indicates that individuals and groups are in terms of the groups to which they belong. Major characteristics are race, ethnicity, language, family background, income status, immigration status, sexual orientation, illness, and religious practice(s) [15].

The social identity of language learners has become a research direction over the past few decades [16-18]. Unlike other language learners, who want to learn a language for academic purposes, business opportunities, or personal enhancement $[19,20]$, some language learners want to gain a social identity and sense of belonging in relation to their original ethnic regions and groups $[17,21]$. Some Spanish-speaking families teach their children at least a beginners' level of Spanish language proficiency, as they want to continue the family heritage and connection from their countries, particularly for children in early childhood [22]. However, as English is the main instructional language in most American public-school systems, children usually study and learn English as their native language in school, at home, and in public areas. Although many of their Spanish-speaking family members, particularly their parents and grandparents, continue to use Spanish as the main language at home, second-generation children only attain a low level of language proficiency, as they have more confidence in their English proficiency [23].

A previous study [24] advocated that language and social identity include four important anthropological elements: practice, indexicality, ideology, and performance. Language use is usually connected to the social identity of the language speakers, listeners, and learners, as they are involved in the language environment, such as their family heritage. In other words, the relationship between language use and social identity is strong in individuals' language learning motivations and reasons. Some scholars [18] have indicated that language is the carrier of the social identity and culture of the learners and speakers. For example, a recent study [25] examined students in a dual Spanish-English classroom environment. The results indicated that the cultural element and spoken environment played an important role(s) in the participants' sense of belonging and language identity.

However, not all heritage speakers select their heritage language as their second language in language classroom environments due to language difficulties, uses, applications, personal interests, and academic developments [26]. Second language refers to any languages (also third or fourth language) learnt in addition to the native language [27]. As for the heritage speakers, in the United States, these are individuals who have been raised with family members who speak at least some language(s) based on their family origin(s) to them but are not currently living in the family origin(s) and has had little or no formal education of that language(s) [28]. A recent study [29] investigated the experiences of a group of Portuguese language learners in American military bases. The researchers advocated that they learnt the Portuguese language due to the workplace environment(s), career opportunities, and the use(s) of the language at the bases. Although heritage and family backgrounds are important elements of foreign language learning motivations and reasons, not all follow the pathways.

The position of foreign language learning is unique. The United States does not have an official language. English is the de facto dominant language in many environments, such as employment in government departments, schools, and social communities. Fishman [11] advocated that any language other than English can be viewed as a heritage language(s) for speakers of that language(s). McCarty [30] argued that English should be the foreign 
language or heritage language as native and indigenous languages and cultures are the original cultures in North America. For the role(s) of Spanish language in the United States, Spanish can be viewed as a colonial heritage language due to the colonial settlements. In the United States, colonial heritage language refers to language(s) of different European countries and groups that colonised and controlled what is now the United States, and which are still used. Spanish is considered as one of the colonial heritage languages [11].

Because of historical factors, Spanish became one of the dominant spoken languages other than English in the United States [4]. From the perspectives of social and identity, a recent study [6] indicated that some Mexican-American people described themselves as Spanglish people due to their unique background(s). Individuals may switch their spoken language(s) under different social backgrounds. In the social communities, they may speak English for general communication. In the heritage language course, they may speak Spanish due to their social identity. However, the participants indicated that not all Spanglish people want to learn Spanish as they are confused about their identity due to their birthplace and place of origin. Therefore, the motivations of learning can be different from group to group.

\subsection{Purpose of the Study}

Family heritage, cultural background, and social identity are some of the motivations and reasons [31] why language learners decide to learn a particular heritage language, in this case, the Spanish language. This study aimed to understand and explore the relationship between social identity and language learning motivation based on the social cognitive career and motivation theory and the social identity theory of a group of Spanish language learners in a university environment in the United States. One research question was employed:

Why do learners want to learn their heritage language, in this case, Spanish? What are the motivations and reasons for wanting to do so?

\section{Theoretical Frameworks}

\subsection{Social Identity Theory}

This study employed two theoretical frameworks: the social identity theory [32,33] and the social cognitive career and motivation theory [34]. The social identity theory is useful to understand individuals' sense of who they are based on their relationship between the groups. The social identity theory indicated that individuals' social identity is based on the self-concepts of the membership of a targeted group, such as the MexicanAmerican ethnic group [35]. Individuals' characters and sense-making processes influence their social behaviours and motivations through their membership within the targeted group(s). Individuals usually maintain a positive understanding of and belief in the groups they belong to [36]. For example, a previous study [37] indicated that cultural and social identities played an important role(s) in heritage language learners' decision-making processes and motivations. Another study [35] also argued that sociocultural and social identity served as the key points in heritage language learning and the decision-making process. In the social identity processes, individuals tend to learn from and maintain connections with their groups, with positive attitudes and behaviours among the in-group members. Although some group members want to distance themselves from their ingroup identity, as out-group members, some of their behaviours and understandings may continue to be influenced by their original heritage and sense of belonging to the group.

\subsection{Social Cognitive Career and Motivation Theory}

Second, the social cognitive career and motivation theory [34,38] was developed based on the social cognitive career theory [39] and the self-efficacy approach [40]. In brief, self-efficacy advocated that if individuals have a strong understanding and self-confidence of their goals and achievements, the individuals may have a higher chance(s) to achieve the goals, and vice versa $[20,41]$. The social cognitive career and motivation theory advocated 
that individuals' motivations and decision-making processes were influenced by internal and external reasons and elements. First, the psychological and internal factors with selfefficacy impacts: (1) academic interests, (2) personal consideration, and (3) achievements of education and career goals. Second, the social external factors impacts: (1) interests in career development, (2) financial considerations, and (3) surrounding environments and individuals $[34,38]$.

The social cognitive career and motivation theory is useful for the investigation of school leadership, language learning, motivation of foreign language learning, and the language learning behaviours of bilingual and heritage language(s). For example, a recent study employed the social cognitive career and motivation theory [42] to understand the decision-making process of a group of kindergarten teachers. The employment of the social cognitive career and motivation theory allowed the researchers to understand the reasons and motivations of teachers' behaviours and ideas. In the current study, the researchers wanted to employ the theory for the investigation of heritage language learning and the motivation of learning. Therefore, the application would be applicable, appropriate, and useful $[34,38]$. Please refer to Figure 1 for the social cognitive career and motivation theory.

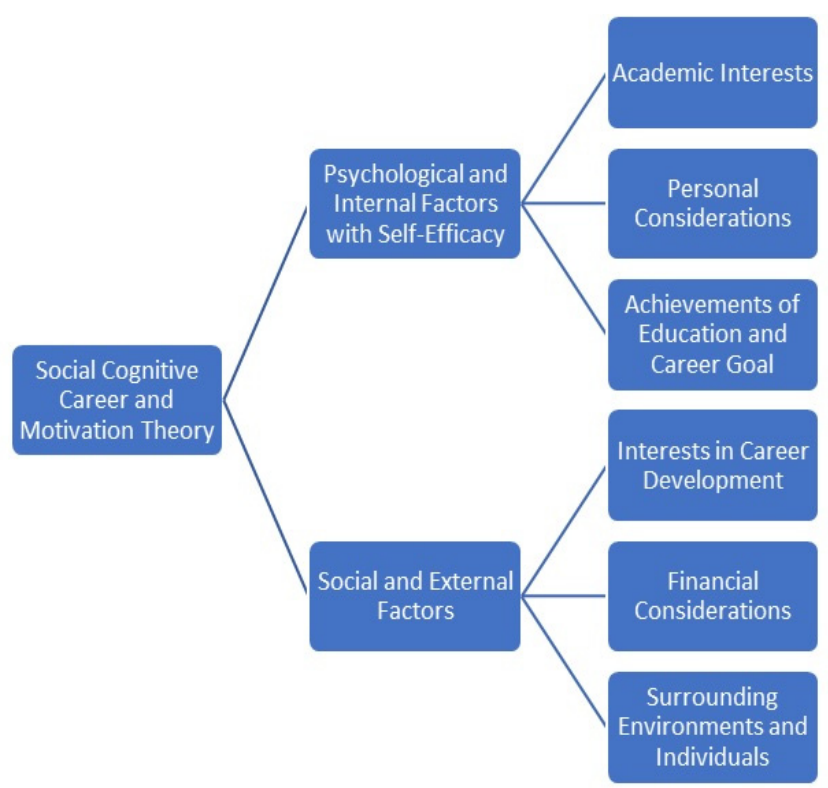

Figure 1. Social cognitive career and motivation theory $[34,38]$.

\section{Materials and Methods}

\subsection{Research Design}

The general inductive approach [43] is used as the research design to collect qualitative data from Spanish heritage learners in one of the university environments in the United States. The general inductive approach argued that qualitative researchers could (1) manage the original data into groups and categories, (2) connect the ideas and directions between the goals and the finding based on the original data, and (3) create the themes and frameworks of the underlying orders and structures from the original data. In order to collect the wider perspective and picture in the current American environment, the researcher employed the general inductive approach as this research design allowed the researcher to gather data from different sites and backgrounds.

\subsection{Recruitment and Participants}

The purposive and snowball sampling strategies were employed [44]. First, the researcher orally invited three Spanish heritage learners who are currently enrolled at one of the Spanish courses for heritage speakers at one of the universities in the United States. Once the participants orally accepted the invitation, the researcher formally sent the 
research statement, data collection procedures, protocol, risk statement, consent form, and related materials to the participants [45]. The participants sent and emailed the consent form to the researcher for confirmation. Then, the researcher arranged the virtual-based, semi-structured, one-on-one, and private interview session(s) for each participant via the social media application. Please note that once the participant completed the interview session, he/she should try their best to refer at least one Spanish heritage speaker who is taking a Spanish language course in the university environment. After several rounds of referrals and discussions, 78 participants were invited. As the aims of this study have the targeted focuses, the participants should meet the following criteria:

- Spanish heritage speaker;

- Latinx Americans;

- Have little or do not have any Spanish language proficiency before the Spanish course at the university;

- University student;

- Currently majoring in an academic major other than Spanish language and literature or a related academic programme;

- At least 18 years old.

\subsection{Data Collection}

Three data collection tools were used: (1) semi-structured interview; (2) focus group activity; and (3) member checking interview. First, according to Creswell [46], the interview tool is one of the common data collection tools in qualitative and social sciences studies. The participants were asked to join a virtual-based, semi-structured, one-on-one, and private interview with the researcher based on the protocol. During the interview session, the researcher asked the participants about their motivations for learning, their sense of belonging, and the decision-making processes of their Spanish language learning and courses. Each interview session lasted from 78 to $112 \mathrm{~min}$.

After all participants completed their interview sessions, the researcher arranged the focus group activities for group sharing. Due to the geographic locations and time differences, the focus group activities were conducted online. Six participants joined each of the focus group activities. Therefore, 13 focus group activities were conducted. Each focus group activity lasted from 167 to $189 \mathrm{~min}$ with two ten-minute breaks.

After all participants completed the data collection procedure, the researcher sent the related parts to the participants for confirmation. The researcher arranged the member checking interview sessions in order to confirm the validity of the qualitative data. The member checking interview sessions were conducted online from 34 to $42 \mathrm{~min}$. All the participants agreed with their parts. Please note that a digital recorder recorded all the data collection sessions. All the participants agreed with the arrangement.

Validity and Triangulation

Validity is one of the important elements in qualitative research studies. In order to ensure validity, the current study employed several tools in order to confirm the qualitative data. First, the researcher employed two data collection tools: semi-structured interview sessions and focus group activities for the data collection. Second, after the researcher collected the qualitative data, the member checking interview sessions were employed for confirmation. The participants confirmed and agreed on their data. Third, multiple theoretical frameworks - the social identity theory and the social cognitive career and motivation theory-were employed. Therefore, with three types of directions, the researcher has ensured the ideas of triangulation for this study.

\subsection{Data Analysis}

After the researcher gathered all the data from the data collection procedure, the researcher transcribed the voiced messages to the written transcripts for the data analysis procedure. The researcher re-read the data multiple times to gather the connections and 
themes. First, the researcher employed the open-coding technique to categorise the firstlevel themes and subthemes. At this point, 15 themes and 12 subthemes, such as living in Mexico and Mexican-American people, were merged. However, further analysis should be conducted. Therefore, the researcher employed the axial-coding technique to further narrow the data [47]. As a result, three themes and three subthemes were yielded as the second-level themes for this study. For the themes, please refer to Table 1. Please note that the current study received support and approval from the Woosong University Academic Research Funding 2021/2022.

Table 1. Themes and subthemes.

Themes and Subthemes

4.1. Americans with Dual Identities: Culture and Heritage

Personal Consideration: My Heritage Culture

4.2. Interests in Career Development

Spanish Language is Useful Internationally

4.3. Surrounding Environments and Individuals

My Family Members Speak Spanish: Understanding of Our Heritage Culture

\section{Results and Findings}

Based on the qualitative sharing and lived stories of 78 Spanish heritage learners who are studying Spanish heritage courses at one university in the United States, the researcher identified three themes and three subthemes. Although these participants' family heritages are located in different parts of the world, all shared that their internal and external interests in Spanish language learning were associated with their ethnic and family heritage. Table 1 outlines the themes and subthemes.

\subsection{Americans with Dual Identities: Culture and Heritage}

Based on the social identity theory [32,33], dual identities played an important role(s) in the motivations and decision-making process of heritage language learning from these 78 participants. All participants used the word "Latinx American(s)" to describe their identities and backgrounds in the United States. Based on the data, the "Latinx American(s)" has been mentioned more than 600 times. The following stories indicated the ideas of dual identities:

... I am not only an American ... I am a Venezuelano and Americano ... in the United States... I do not and cannot forget I am a Venezuelano because my father and mother also remind us [siblings] our family heritage in Venezuela ... so I want to learn Spanish at college ... so I can join my language and culture again ... (Participant \#34, Focus Group).

... I did not live in Peru previously ... but I miss Peru, and I want to go back to Peru ... for a non-profit organisation ... for some children and children in the remote village ... perhaps this is my mission as a Peruvian because we have to contribute our energy back to our country ... I mean both the United States and Peru ... (Participant \#77, Focus Group).

All 78 participants were Americans with heritage backgrounds in a Spanish-speaking country in Central or South America. Although all have previously been to their country of origin with family members, to visit or live there, all had only a beginners' level or no Spanish language proficiency before starting their Spanish course. However, based on their sharing, it is evident that the participants wanted to keep speaking Spanish to maintain a connection with their country of origin. Two stories were captured in this respect:

... I could only speak a little Spanish ... but I think it is not good ... my mother told us that we are from Mexico ... my parents, grandparents, and cousins were born in Mexico ... it is important to have our origin roots, which I agreed with ... I think 
college is a good place for me to start my language and my identity ... (Participant \#21, Interview).

... many Latino people believe their language and culture are the social connections ... with their country ... I was born in the United States ... but I think I have a very strong connection with my country ... Argentina in South America ... I went to Argentina with I was in middle school and high school ... I love that country and I want to contribute my energy to my homeland and people in my homeland ... understanding the language and culture is the first step... (Participant \#45, Interview).

In short, in lines with the social identity theory $[32,33]$ and the social cognitive career and motivation theory [34,38], participants believed that their dual social identity, culture and heritage influenced their language learning motivation.

\section{Personal Consideration: My Heritage Culture}

The researcher further asked about the elements and factors that made the participants learn Spanish instead of Chinese, French, or Italian (other popular language learning pathways and courses in the United States). Many believed that the heritage culture(s) and family culture(s) played an important role(s) in their decision-making processes, motivations, and selections. To illustrate this idea, a participant shared a story about their daily use of language and vocabulary, expressions, and slang, which consisted of a mix of English and Spanish:

... it isn't polite to call my mom's first name in our culture ... we have to call mom, mother, or Madre in Spanish ... we don't call our school as school ... we used the Spanish word escuela ... as my school ... I cannot form a whole sentence in Spanish ... but we all used some vocabulary and terms in Spanish because my mom always speaks Spanish at home... over the years, I gained the sense of mind ... of my origin ... perhaps dual origins ... the US and Cuba ... (Participant \#58, Interview).

Besides the language applications and uses of both English and Spanish, many participants indicated that they watched TV shows and news from their place(s) of origin, ate food in non-American styles and dressed according to their family's heritage(s) and cultural background(s). For example, in terms of the food and cooking styles at home, many indicated that they always ate taco, salsa, churros, elote, and horchata as daily meals. One significant story was captured in this respect:

... my mother always cook Yerba mate and Asado at home for dinner ... these are traditional Argentinean food ... my parents always told us that we are Argentineans and also Americans ... but I could only listen to Spanish because I was too lazy to learn ... but now, I want to gain some cultural understanding of my place of origin ... Spanish language learning is a good start ... (Participant \#29, Focus Group).

In short, in lines with the social identity theory [32,33] and the social cognitive career and motivation theory [34,38], heritage, family, and practical cultures played an important role(s) in the decision-making processes, motivations, and selections of these groups of participants, particularly in the areas of language learning. The following section outlined the theme of interests in career development.

\subsection{Interests in Career Development}

In line with the social cognitive career and motivation theory $[34,38]$, the ideas about career developments, career pathways, and job promotions were mentioned more than 300 times. Many participants indicated their interests in Spanish language learning for the sake of furthering their business or career developments. The researcher captured two interesting stories in this respect:

... we have many Mexican and Central American people in the southern Texas region

... a big need for the Spanish speaking professionals in all industries in Texas ... as I 
am working on my nursing major ... I think I can use my Spanish language skills to help the patients who cannot speak English or else... (Participant \#33, Interview)

... Spanish is very important and useful in the US because we have a lot of Spanish speaking population who do need help in public health ... many of the current services are in English ... what about the Spanish speaking communities? They also need health promotions and suggestions ... if I can speak good Spanish, I can help the US population and the immigrants from Central and South America ... (Participant \#8, Interview).

Spanish Language Is Useful Internationally

The Spanish language is one of the most spoken languages internationally. Currently, except for Brazil, the Falkland Islands, French Guiana, Guyana, and Suriname, the most commonly spoken language in Central and South America is Spanish. Spanish is also one of the official languages of the European Union, as Spain is a member state [48]. In other words, Spanish is widely used in both the United States and Europe. All participants expressed their interests in Spanish language learning (because of their family and cultural heritage). More importantly, many participants wanted to return to their place of origin in order to contribute to and develop their sense(s) of belonging and family heritage(s). Two stories were captured in this regard:

... I know in many South American countries ... patients need help in their basic health development ... many non-profit organisations also need our knowledge and technologies ... as a part of the South American families ... I really want to transfer my knowledge to the organisations in the rural communities ... I have my mission because I am a South American ... (Participant \#3, Focus Group).

... Mexican and other Central American people always help our community members ... in California, we have a very strong Spanish speaking community because we share the same heritage, language, culture, and belief ... I grew up in a Spanish-speaking community ... I can see, I should spend my energy back to the Spanish-speaking communities in Mexico ... (Participant \#14, Interview).

In short, in line with the social cognitive career and motivation theory [34,38], career developments and job promotions became some of the motivations for language learning of these participants. In line with the social identity theory [32,33], many advocated that they would contribute their energies and future developments in some Spanish-speaking countries because of their sense(s) of belonging and cultural heritage(s). The following section outlined the influences of surrounding environments and individuals.

\subsection{Surrounding Environments and Individuals}

The surrounding environments and individuals played an important role(s) in the participants' language learning decision-making processes and motivations [34,38]. Although English is still the dominant spoken language in the United States, it is not hard to find Spanish-speaking communities across the country, particularly in many metropolises and southern regions. The phrase "Spanish-speaking community" was mentioned over a hundred times from the qualitative data. A story was captured in this respect:

... I grew up in little Mexico or the Mexican neighbourhood in my childhood ... I read the Spanish writing and reading all over the street ... we had a very big Mexican population in middle school and high school ... many of our teachers could speak at least two languages, mostly Spanish ... the local government supports the Spanish-speaking communities ... therefore, I have a strong mind about my family heritage in Mexico ... so I want to learn Spanish or at least speak some Spanish ... as I am a Mexican-American ... (Participant \#37, Focus Group).

My Family Members Speak Spanish: Understanding of Our Heritage Culture

In line with the social cognitive career and motivation theory [34,38], besides environmental influences, individual and family influences also played important role(s) 
in the sense-making processes, sense of belonging, decision-making processes, and language learning motivations of the participants [49]. In this case, all indicated that many of their family members could speak Spanish fluently. Their family members' multilingual skills and proficiencies increased the participants' language learning motivations, as they wanted to understand the conversations at family gatherings. One story was captured in this respect:

... I want to speak the language from my cousins, uncles, aunts, and even my parents

... during the family gathering, I cannot speak and understand the conversation because

I cannot speak the language ... I am a part of the family ... but I felt that I am not a part of them ... I belong to the Spanish speaking group ... but I cannot understand the ideas from these people ... I have to learn that because I am a part of them ... (Participant \#65, Focus Group).

In short, in line with the social identity theory [32,33], participants believed that their family, family culture, and family roles drove their motivations of learning, such as the family heritage in Mexico. In line with the social cognitive career and motivation theory $[36,40]$, the surrounding environments and individuals drove their motivations of learning as they want to gain the in-group identity from their family members.

\section{Discussion}

Heritage background(s) played an important role(s) in the language learning decisionmaking process and dual identity as a Latinx American (i.e., this was captured more than 600 times). In line with the social identity theory [32,33], many participants advocated that language(s) and culture(s) are key factors connecting their personal beliefs and social identity as Latinx Americans with their family heritage(s) in Latino countries and regions. Reflecting on some previous studies [4,5,50,51], cultural roots and the social identity of an individual's country of origin play an important role(s) in language learning, particularly in heritage language learning and motivations. In their stories, the participants showed a significant belief in the connection between a sense of belonging and language learning decision-making processes (based on heritage).

One possible reason and motivation revealed by the data seemed to be the social and peer influences [16-18]. In this case, the participants believed that their dual identities and heritage culture drove their motivations for learning. In line with the social cognitive career and motivation theory [34], all participants indicated that their heritage culture(s) and living practice(s) were linked to their personal understanding, self-identity, and language learning motivations as a whole. The finding confirmed the arguments from Lynch [50] that if students have the sense of belonging (e.g., to their heritage), their motivations can be established.

From the perspective of food and home activities, with reflection on a previous study [6], food and cultural connections could be a primary influence in regard to the participants' original culture(s) and family heritage(s), as their parents reminded them of their heritage(s). In line with the social cognitive career and motivation theory [34], psychological and internal factors, self-efficacy, and personal considerations significantly influenced the language learning motivations and decision-making processes of these groups of heritage language learners. The combination of linguistic and cultural understandings and language selection confirmed that personal considerations played important roles [23].

As a previous study [12] showed, many Spanish-speaking residents live in different parts of the United States. In other words, the expansion of Spanish-speaking communities may significantly increase the career opportunities of Spanish-speaking candidates. In line with the social cognitive career and motivation theory [34], almost all participants expressed their interests in career developments based on their Spanish language proficiencies and the opportunities associated with Spanish language communities. Furthermore, some previous studies $[52,53]$ advocated that financial consideration played an important role in language learning and learning motivations. The development of language proficiencies 
helps their career development. In line with the social identity theory [32,33], Spanish is their selection due to their social identity.

It is evident that family heritage(s) and sense(s) of belonging are significantly associated with the language learning motivations of these groups of Spanish language learners. With the reflection of the social identity theory [32,33], the participants' ideas about in-group membership and family heritage(s) were associated with their decision-making processes, particularly in the way in which they described their identities and their motivations for learning Spanish. Some previous studies [50,51] also suggested that culture(s) may enable second generations to catch up with their linguistic and cultural backgrounds. Therefore, it is confirmed that the participants' social identities as Spanish-speaking professionals and individuals influenced their decision-making processes in line with the social cognitive career and motivation theory [34].

According to a recent report [13], 22 American cities and towns have more Spanish speakers than English speakers. Therefore, many participants grew up in Spanish-speaking communities during their childhood and teenage years, among Spanish-oriented individuals and environments. In line with the social identity theory [32,33], the current study found that some participants (e.g., Participant \#64) believed that their childhood and teenage experiences in the Spanish communities played an important role in their language learning motivations (as they have established the sense of belonging). In line with the social cognitive career and motivation theory [34], the surrounding environment played an important role in the sense-making processes, sense of belonging, decision-making processes, and language learning motivations of the participants. A language learning expert, Dornyei [54-56], strongly advocated that individuals' language learning motivations and sense-making processes are greatly influenced by the surrounding environment. This idea also echoes Vygotsky's $[57,58]$ theories about socio-influences and connections with individuals' communities and social environments. This study confirmed that the surrounding environment is associated with the research aims [34]. Reflecting the social identity theory $[32,33]$, the participants strongly indicated that in-group ideas, a sense of belonging to their family heritage(s) and place(s) of origin, and cultural belonging within Spanish-speaking communities were important to them. It is worth noting that a sense of belonging played an important role in the participants' motivations for learning. Therefore, the findings of this study confirmed the connections between social identity and language learning motivations with the reflection of the social cognitive career and motivation theory [34].

\section{Limitations and Further Development}

Four limitations and future research directions were categorised. First, the current study only covered the participants who are currently taking the heritage Spanish language courses at the university level. However, middle schools and high schools in the current American education systems offer similar courses. Therefore, future research studies may further investigate the current problems and issues at the secondary school education and school environment level, in order to determine the wider picture.

Second, based on the spoken language statistics and reports, Chinese and Vietnamese are some of the top-spoken languages in the United States. Although the Spanish language is widely used in many social backgrounds and communities, the application of other minorities languages should be concerned. In the future, researchers should expand the (foreign) language learning investigations to other languages for a wider understanding.

Third, the current study only covered the issues and problems in the United States. Other countries and regions also face similar issues and problems. Therefore, future research studies may further investigate the problems in heritage language teaching and learning in order to have a greater picture in the field of language learning education.

Fourth, this study only collected data from the qualitative method. However, heritage language learners are located in many regions and parts of the United States. Although people may have similar ideas and backgrounds, a larger population and comments from 
different parts of the United States may be useful. Therefore, future research studies may employ the mixed methodology to increase other people's voices and ideas.

\section{Contributions and Conclusions}

Three contributions can be categorised. First, secondary school leaderships and foreign language department heads may use the results of this study to establish additional heritage language learning programmes and courses for heritage language speakers in the American school environments. The results showed that many heritage speakers would like to gain some language proficiency from their family heritage and place of origin. As this study took Spanish as the means for investigation, other languages, such as Chinese and Vietnamese, should have their roles and demands. Therefore, the results may become one of the strongest factors encouraging the Department of Education to provide additional support for these language courses and programmes.

Second, the United States is a multi-cultural country with nearly a thousand spoken languages spoken and used in American communities. Government leaders and policymakers should establish additional programmes and supports for foreign language and minority language teaching and learning. Although English is one of the strongest languages internationally, American people should understand additional languages in order to meet the expectations of our global communities.

Third, currently, not all Americans may be fluent in any foreign languages. The results of this study provided a blueprint for the Department of Education, government leaders, policymakers, school leaders, and researchers to reform and polish the current foreign language teaching and learning programmes in order to increase the percentage and application of foreign language speakers in the United States. As many people in Asia and Europe may handle at least two languages, it is important for American people to understand multiple languages and cultures in order to meet the expectation in the current century.

Funding: This research was funded by Woosong University Academic Research Funding 2021.

Institutional Review Board Statement: The study was conducted according to the guidelines of the Declaration of Helsinki, and approved by the Woosong University (2021-01-01-2021-10-01).

Informed Consent Statement: Informed consent was obtained from all subjects involved in the study. Written informed consent for publication must be obtained from participating patients who can be identified. Written informed consent has been obtained from the patient(s) to publish this paper.

Data Availability Statement: Data available upon request. However, due to human subject protection, some materials were deleted and destroyed.

Conflicts of Interest: The authors declare no conflict of interest.

\section{References}

1. Ranking of Languages Spoken at Home in the U.S. 2019. Available online: https://www.statista.com/statistics/183483/rankingof-languages-spoken-at-home-in-the-us-in-2008/ (accessed on 31 August 2021).

2. Looney, D.; Lusin, N. Enrollments in Languages Other than English in United States Institutions of Higher Education, Summer 2016 and Fall 2016: Final Report; Modern Language Association: New York, NY, USA, 2019.

3. Palmer, R.; Maramba, D. Racial microaggressions among Asian American and Latino/a Students at a historically black university. J. Coll. Stud. Dev. 2015, 56, 705-722. [CrossRef]

4. Valdes, G. Heritage language students: Profiles and possibilities. In Heritage Languages in America: Preserving a National Resource; Peyton, J., Ranard, D., McGinnis, S., Eds.; Center for Applied Linguistics \& Delta Systems: Washington, DC, USA; McHenry, IL, USA, 2001; pp. 37-77.

5. Valdes, G. Learning and Not Learning English: Latino Students in American Schools; Teachers College Press: New York, NY, USA, 2001.

6. Showstack, R. Spanish and identity among Latin@s in the U.S. In The Routledge Handbook of Spanish as a Heritage Language; Potowski, K., Muñoz-Basols, J., Eds.; Routledge: New York, NY, USA, 2018; pp. 92-106.

7. Potowski, K. Spanish as a heritage/minority language. In The Routledge Handbook of Spanish as a Heritage Language; Potowski, K., Muñoz-Basols, J., Eds.; Routledge: New York, NY, USA, 2018; pp. 1-14. 
8. Soler, I.G. Spanish heritage language learners in Tennessee: Current practices, challenges, and directions for the future. In Spanish across Domains in the United States; BRILL: Leiden, The Netherlands, 2020; pp. 121-152.

9. Beaudrie, S.M. Towards growth for Spanish heritage programs in the United States: Key markers of success. Foreign Lang. Ann. 2020, 53, 416-437. [CrossRef]

10. Helmer, K.A. Learning and Not Learning in the Heritage Language Classroom; Multilingual Matters: Bristol, UK, 2020; ISBN 9781788927642.

11. Fishman, J. 300-plus years of hertiage language education in the United States. In Heritage Languages in America: Preserving a National Resource. Language in Education: Theory and Practice; Peyton, J., Ranard, D., McGinnis, S., Eds.; Center for Applied Linguistics \& Delta Systems: Washington, DC, USA; McHenry, IL, USA, 2001; pp. 81-98.

12. Buchholz, K. Where Spanish Speakers Live in the U.S.; New York, NY, USA, 2019. Available online: https:/ / www.statista.com/ chart/17521/spanish-speaker-in-the-us-by-state/ (accessed on 15 November 2021).

13. Akhtar, A.; Kiersz, A. Here Are the 22 US Cities and Towns with More Spanish than English Speakers. Insider 2019. Available online: https: / / www.businessinsider.in/slideshows/miscellaneous/here-are-the-22-us-cities-and-towns-with-more-spanishthan-english-speakers/slidelist/69982001.cms\#slideid=69982016 (accessed on 15 November 2021).

14. Bowles, M.A. Outcomes of classroom Spanish heritage language instruction. In The Routledge Handbook of Spanish as a Heritage Language; Potowski, K., Muñoz-Basols, J., Eds.; Routledge: New York, NY, USA, 2018; pp. 331-344.

15. Tajfel, H. Social Identity and Intergroup Relations; Cambridge University Press: Cambridge, UK, 2010.

16. Gao, X.; Lamb, T. Exploring links between identity, motivation and autonomy. In Identity, Motivation and Autonomy in Language Learning; Murray, G., Gao, X., Lamb, T., Eds.; Multilingual Matters: Bristol, UK, 2011; pp. 1-8.

17. Norton, B.; Toohey, K. Identity, language learning, and social change. Lang. Teach. 2011, 44, 412-446. [CrossRef]

18. Tong, Y.; Hong, Y.; Lee, S.; Chiu, C. Language use as a carrier of social identity. Int. J. Intercult. Relat. 1999, 23, 281-296. [CrossRef]

19. Džuganová, B. Teaching medical English through professional captioning videos. J. Lang. Cult. Educ. 2019, 7, 95-107. [CrossRef]

20. Kwee, C.T.T. I want to teach sustainable development in my English classroom: A case study of incorporating sustainable development goals in English teaching. Sustainability 2021, 13, 4195. [CrossRef]

21. Gardner, R.C. Language learning motivation: The student, the teacher, and the researcher. Texas Pap. Foreign Lang. Educ. 2001, 6, $1-18$.

22. Mancilla-Martinez, J.; Lesaux, N.K. Early indicators of later English reading comprehension outcomes among children from Spanish-speaking homes. Sci. Stud. Read. 2017, 21, 428-448. [CrossRef]

23. Alfonso, S.V.; Lonigan, C.J. Executive function, language dominance and literacy skills in Spanish-speaking language-minority children: A longitudinal study. Early Child. Res. Q. 2021, 57, 228-238. [CrossRef]

24. Bucholtz, M.; Hall, K. Language identity. In A Companion to Linguistic Anthropology; Duranti, A., Ed.; Blackwell: London, UK, 2004; pp. 369-394.

25. Martínez, R.A.; Durán, L.; Hikida, M. Becoming "Spanish Learners": Identity and interaction among multilingual children in a Spanish-English dual language classroom. Int. Multiling. Res. J. 2017, 11, 167-183. [CrossRef]

26. Long, A.Y.; Geeslin, K. Spanish second language acquisition across the globe: What future research on non-English speaking learners will tell us. Hispania 2017, 100, 205-210. [CrossRef]

27. Rieder-Bünemann, A. Second language learning. In Encyclopedia of the Sciences of Learning; Seel, N., Ed.; Springer: Boston, MA, USA, 2012; pp. 2980-2983.

28. Baker, C.; Jones, S. Encyclopedia of Bilingual Education and Bilingualism; Multilingual Matters: Clevedon, UK, 1998.

29. Miller, Z.F.; Crowther, D. Foreign language learning motivation in a U.S. military academy: A comparative case study on the effects from the learning environment. Appl. Lang. Learn. 2020, 30, 41-59.

30. McCarty, T.L. A Place to be Navajo: Rough Rock and the Struggle for Selfdetermination in Indigenous Schooling; Lawrence Erlbaum: Mahwah, NJ, USA, 2002.

31. Gao, X. Shifting motivational discourses among mainland Chinese students in an English medium tertiary institution in Hong Kong: A longitudinal inquiry. Stud. High. Educ. 2008, 33, 599-614. [CrossRef]

32. Tajfel, H.; Turner, J. The social identity theory of intergroup behaviours. In Psychology of Intergroup Relations; Worchel, S., Austin, W.G., Eds.; Nelson-Hall Publishers: Chicago, IL, USA, 1986; pp. 7-24.

33. Tajfel, H. Cognitive aspects of prejudice. J. Biosoc. Sci. 1969, 1, 173-191. [CrossRef]

34. Dos Santos, L. Motivations and career decisions in occupational therapy course: A qualitative inquiry of Asia-Pacific international students in Australia. Adv. Med. Educ. Pract. 2021, 12, 825-834. [CrossRef]

35. He, A.W. The heart of heritage: Sociocultural dimensions of heritage language learning. Annu. Rev. Appl. Linguist. 2010, 30, 66-82. [CrossRef]

36. Shin, S.J. "What about me? I'm not like Chinese but I'm not Like American": Heritage-language learning and identity of mixed-heritage adults. J. Lang. Identity Educ. 2010, 9, 203-219. [CrossRef]

37. Lee, J.S. The Korean language in America: The role of cultural identity in heritage language learning. Lang. Cult. Curric. 2002, 15, 117-133. [CrossRef]

38. Dos Santos, L. Developing bilingualism in nursing students: Learning foreign languages beyond the nursing curriculum. Healthcare 2021, 9, 326. [CrossRef] 
39. Lent, R.W.; Brown, S.D.; Hackett, G. Toward a unifying social cognitive theory of career and academic interest, choice, and performance. J. Vocat. Behav. 1994, 45, 79-122. [CrossRef]

40. Bandura, A. Social Foundations of Thought and Action: A Social Cognitive Theory; Prentice-Hall: Englewood Cliffs, NJ, USA, 1986.

41. Dos Santos, L.M. Stress, burnout, and low self-efficacy of nursing professionals: A qualitative inquiry. Healthcare 2020, 8, 424 . [CrossRef]

42. Dos Santos, L.M. The relationship between workforce sustainability, stress, and career decision: A study of kindergarten teachers during the COVID-19 pandemic. Sustainability 2021, 13, 11521. [CrossRef]

43. Thomas, D.R. A general inductive approach for analyzing qualitative evaluation data. Am. J. Eval. 2006, 27, 237-246. [CrossRef]

44. Merriam, S.B. Qualitative Research: A Guide to Design and Implementation; Jossey Bass: San Francisco, CA, USA, 2009.

45. Seidman, I. Interviewing as Qualitative Research: A Guide for Researchers in Education and the Social Sciences, 4th ed.; Teachers College Press: New York, NY, USA, 2013.

46. Creswell, J. Qualitative Inquiry and Research Design: Choosing among Five Approaches, 4th ed.; Sage: Thousand Oaks, CA, USA, 2012.

47. Strauss, A.; Corbin, J.M. Basics of Qualitative Research: Grounded Theory Procedures and Techniques; Sage: Thousand Oaks, CA, USA, 1990.

48. Steward, M. The Spanish Language Today; Routledge: London, UK, 1999; ISBN 9780415142595.

49. Ortega, L. The study of heritage language development from a bilingualism and social justice perspective. Lang. Learn. 2020, 70, 15-53. [CrossRef]

50. Lynch, A. A Historical view of US Latinidad and Spanish as a heritage language. In The Routledge Handbook of Spanish as a Heritage Language; Potowski, K., Muñoz-Basols, J., Eds.; Routledge: New York, NY, USA, 2018; pp. 17-35.

51. Hur, E.; Lopez Otero, J.C.; Lee, E. Attitudes and expectations towards heritage language instruction: Evidence from Korean and Spanish in the US. Languages 2021, 6, 14. [CrossRef]

52. Dos Santos, L.M. I want to become a registered nurse as a non-traditional, returning, evening, and adult student in a community college: A study of career-changing nursing students. Int. J. Environ. Res. Public Health 2020, 17, 5652. [CrossRef] [PubMed]

53. Carter, P.M. Spanish in U.S. language policy and politics. In The Routledge Handbook of Spanish as a Heritage Language; Potowski, K., Muñoz-Basols, J., Eds.; Routledge: New York, NY, USA, 2018; pp. 36-52.

54. Dörnyei, Z. Conceptualizing motivation in foreign-language learning. Lang. Learn. 1990, 40, 45-78. [CrossRef]

55. Dörnyei, Z. Motivation in second and foreign language learning. Lang. Teach. 1998, 31, 117-135. [CrossRef]

56. Ushioda, E.; Dornyei, Z. Beyond global English: Motivation to learn languages in a multicultural world. Mod. Lang. J. 2017, 101, 451-454. [CrossRef]

57. Vygotsky, L.S. Mind in Society: The Development of Higher Psychological Processes; Cole, M., John-Steiner, V., Scribner, S., Souverman, E., Eds.; Harvard University Press: Cambridge, MA, USA, 1978.

58. Vygotsky, L.S. The genius of high mental functions. In The Concept of Activity in Soviet Psychology; Wertsch, J., Ed.; Sharpe: Armonk, NY, USA, 1981; pp. 144-188. 